\title{
DETERMINANTS OF E-COMMERCE ADOPTION: EVIDENCE FROM SMALL AND MEDIUM-SIZED ENTERPRISES IN INDIA
}

\author{
R. Sujatha* \\ PSG Institute of Management, India \\ M. S. Karthikeyan \\ PSG Institute of Management, India
}

\begin{abstract}
Information technology (IT) is driving the business world in contemporary times. Large, medium, and small organisations in developed and developing countries are trying to adopt electronic commerce (e-commerce). Small and medium-sized enterprises (SMEs) are abundant in India, which is a rapidly developing country. Despite enormous efforts to adopt e-commerce, SMEs must address many hurdles. The major objective of this paper is to investigate the determinant factors that influence the adoption of e-commerce in SMEs. In this study, three categories and a three-stage model were used to demonstrate the various factors and stages that are involved in the adoption of e-commerce. A structured survey was conducted and data was collected from 148 firms in Coimbatore, a major industrial city in India. The data was analysed using binomial logistic regression to determine a significant relationship between a set of independent variables and the dependent variable. The results indicated that Top Management Support, Learning Orientation, Receptivity towards Change, Strategic Orientation, IT Readiness, Cost, and Relative Advantage as statistically significant determinants of e-commerce adoption. This study provides insight to the managers of organisations who are responsible for implementing e-commerce, and it will help to spread e-commerce use across SMEs in India.
\end{abstract}

Keywords: Developing Country, E-Commerce Adoption, Internet, Small and Medium-Sized Enterprises.

Received: 27 February 2019

Accepted: 10 May 2021

https://doi.org/10.33736/ijbs.3740.2021

\section{INTRODUCTION}

The three most powerful forces driving the world economy are globalisation, liberalisation, and information and communication technologies (ICTs). The exponential growth of ICT in recent years has resulted in the emergence of electronic commerce (e-commerce) that has changed the current business world. Organisations have redefined their business processes and models using technology to change how products and services are conceived, marketed, and delivered (Chaudhury \& Kuilboer, 2002). Turban et al. (2002) defined e-commerce as the process of buying, selling, or exchanging products, services, and information using a computer network. According to Electronic Commerce Team of European Union, 'Electronic Commerce refers specially to buying and selling of products and services through internet' (Schulze \& Baumgartner, 2000). The

\footnotetext{
- Corresponding author: PSG Institute of Management, Post Box No. 1668, Peelamedu, Coimbatore-641 004, Tamil Nadu, India; Phone: +91-422-4304400; Email: sujatha@psgim.ac.in
} 
World Trade Organization defines e-commerce as 'production, distribution, marketing, sale and delivery of goods and services by electronic means'. As various definitions have evolved for ecommerce, this study adopted the description provided by Globerman et al. (2001) to define ecommerce as 'any economic transaction where the buyer and seller come together through the electronic media of Internet, form a contractual agreement concerning the price and delivery of goods and services, and complete the transaction through the payment as contracted'.

E-commerce offers unique opportunities for organisations in developed and developing countries. However, businesses in developing countries are still reluctant to infuse e-commerce into their business processes. They appear less engaged in e-commerce compared with businesses in developed countries such as United States and European countries (Jon et al., 2001). E-commerce adoption in developing countries is more complex because of challenges, such as insufficient technology, insufficient regulatory measures, and inadequate infrastructure (Titi, 2005). In the short term, gains are likely to be concentrated in developed countries; however, in the long term, developing countries have more to benefit from adoption of e-commerce (Rahayu \& Day, 2017; Terzi, 2011). This study is significant for several reasons. It fills the knowledge gap about ecommerce diffusion in a developing country such as India and aims to investigate the e-commerce usage-profile of small and medium-sized enterprises (SMEs). In addition, factors that affect their willingness to adopt e-commerce in a major industrial city of India are explored.

\section{LITERATURE REVIEW}

SMEs are the backbone of a country's economy. However, e-commerce adoption in SMEs is limited because their characteristics differ from those of large organisations. SMEs have small management teams, strong owner influence, low employee turnover, and are reluctant to take risks (Kreiser et al., 2010). Owing to their smaller size and risks involved, SMEs have a strong reluctance to adopt any new technology. Marasini et al. (2008) highlighted that there is an inherent need for development of low-cost reliable solutions tailored to meet the needs of SMEs. They have listed the inhibiting factors for the adoption of e-commerce as fear of information technology (IT), resistance to change, trust, commitment of time, high initial set-up cost, costs incurred because of the change, weak skill base, security/privacy issues, lack of training opportunities and networking, ownership of data, intellectual property, lack of awareness about ICT, and lack of proven best practice examples. Chong (2008) carried out a cross-country study about SMEs and observed that factors such as observability, communication channels, customer pressure, supplier pressure, and perceived government support significantly contribute towards adoption of Internet-based ecommerce. Seyal et al. (2007) indicated the factors for adoption of e-commerce in SMEs as organisational readiness, organisational culture, top management support, motivation to use, environmental factors, government support, technological factors, perceived benefits, and task variety. Oliveira and Martins (2010) studied e-commerce adoption and indicated that perceived benefits, technology readiness, technology integration, firm size, competitive pressure, and trading partner collaboration influence e-commerce adoption. Li and Xie (2012) summarised managerial attitudes, corporate strategies, external pressures, and firms' technological strengths as the factors that determine adoption of e-commerce. Zaied (2012) highlighted that e-commerce is much more than a tool to improve cost-quality ratios in SMEs' services. He investigated the factors that influence and inhibit the implementation of e-commerce in SMEs and observed that SMEs adopted only basic applications. Zaied (2012) further reiterated that lack of security, limited use of Internet, 
planning and implementation of e-commerce, and culture and social structure of the organisation influenced the adoption.

Al-Alawi and Al-Ali (2015) identified that organisational context (top management support), technological context (perceived benefits), and environmental context (government regulations) are positively related to e-commerce adoption. Ahmad et al. (2015) empirically tested and demonstrated that e-commerce adoption in SMEs is affected by perceived relative advantage, perceived compatibility, managers/owners' knowledge and expertise, management characteristics, and external change agents. Rahayu and Day (2015) proposed eleven variables as factors and observed that perceived benefits, technological readiness, owner's innovativeness, owner's IT ability, and owner's IT experience are the determinant factors that influence e-commerce. Awiagah et al. (2016) developed a practical framework to understand e-commerce adoption among SMEs using technological, organisational, and environmental determinants. They observed that government support, managerial support, influence of enabling, and regulatory conditions play a vital role in stimulating e-commerce adoption. Masarweh et al. (2016) suggested that infrastructure, societal trends, culture, and computer literacy are the major determinants of ecommerce adoption. Hussein and Baharudin (2017) conducted a case study research and determined that security, online payment, awareness of e-commerce, and external IT support are factors that inhibit e-commerce adoption. Ramdansyah and Taufik (2017) elaborated that compatibility, top management support, organisational readiness, perceived benefits, and external drive are the factors that support SMEs to adopt e-commerce.

Literature has identified various factors that positively influence and the barriers that inhibit adoption of e-commerce across SMEs. The literature on e-commerce is in the nascent stage and still evolving; there is also limited research on the adoption and practice of e-commerce among SMEs in India. Hence, this study is of relevance in this context. Based on the literature review, the major categories identified for this study are organisational readiness, technological factors, and innovative factors. The constructs under organisational readiness are top management support, organisational competence, learning orientation, receptivity towards change, and strategic orientation (Al-Somali et al., 2015). The technological factors are the internal and external technologies that are relevant to the firm and include constructs such as IT readiness, cost of implementation, and security concerns (Al-Somali et al., 2015). Innovative factor is based on innovation diffusion theory and postulates the five factors of technology adoption, namely relative advantage, complexity, compatibility, trialability, and observability (Rogers, 1995).

When a company attempts to adopt e-commerce, it follows some model to implement it (Cooper \& Zmud, 1990; Ghobakhloo \& Tang, 2013; Rogers, 1995; Zaltman et al., 1973). The technology acceptance model has been used in SMEs to explain usage, behaviour, and attitude towards ecommerce adoption (Belkhamza \& Wafa, 2009; Nezakati et al., 2012). The theory of acceptance and use of technology has been used to understand e-commerce adoption in developing countries by Ndayizigamiye (2012). The diffusion of innovation theory has been applied to understand ecommerce adoption in SMEs (Al-Qirim, 2005; Moghavvemi et al., 2012). The technology organisation environment framework was used to understand e-commerce adoption by Huy et al. (2012). The theory of planned behaviour was used by Parker and Castleman (2009), and the resource-based theory was used by Zhao et al. (2008). Molla and Licker (2005a, 2005b) proposed a two-stage model of e-commerce adoption, and Cooper and Zumd (1990) proposed a six-stage model for IT implementation in an organisation. Different studies have suggested different models 
to classify stages of the e-commerce adoption process. However, in this study, the three-stage model proposed by Al-Somali et al. (2015) is used. This model was researched in a 'developing' country. Using the model in a similar developing country like India is an added advantage because the model will be able to evaluate the factors of e-commerce adoption in a similar cultural and environmental context. The benefit of using this stage-oriented model is that it can simultaneously measure stage and factor effects, which other models cannot do. This type of model can be used in organisations that differ in their level of e-commerce adoption, varying from the very simple use of email to using more complex platforms to deliver services. The three stages of e-commerce adoption process are 'Non-Interactive e-commerce' adoption, 'Interactive e-commerce' adoption, and 'Stabilised e-commerce' adoption. Non-interactive e-commerce adoption refers to the decision to invest in e-commerce. Organisations use the Internet as a bulletin board for brochures, employee telephone directories, and for other documents such as catalogues and price lists (Hartman et al., 2000). Interactive adoption is the presence of an interactive website establishing two-way communication or interactions with users. Stabilisation is the adoption of e-commerce in an organisation's core activities (i.e. product selling, order tracking, and relationship management) and organisational members becoming experienced e-commerce users (Molla \& Licker, 2005a). Based on literature review, the following hypotheses are proposed for the study:

H1.1, H1.2, H1.3: Top Management Support contributes significantly to Non-Interactive Adoption, Interactive Adoption, and Stabilisation of e-commerce.

$\mathrm{H} 2.1, \mathrm{H} 2.2, \mathrm{H} 2.3$ : Organisational Competence contributes significantly to Non-Interactive Adoption, Interactive Adoption, and Stabilisation of e-commerce.

H3.1, H3.2, H3.3: Learning Orientation contributes significantly to Non-Interactive Adoption, Interactive Adoption, and Stabilisation of e-commerce.

H4.1, H4.2, H4.3: Receptivity towards Change contributes significantly to Non-Interactive Adoption, Interactive Adoption, and Stabilisation of e-commerce.

H5.1, H5.2, H5.4: Strategic Orientation contributes significantly to Non-Interactive Adoption, Interactive Adoption, and Stabilisation of e-commerce.

H6.1, H6.2, H6.3: IT Readiness contributes significantly to Non-Interactive adoption, Interactive adoption, and Stabilisation of e-commerce.

H7.1, H7.2, H7.3: Cost contributes significantly (negatively associated) to Non-Interactive Adoption, Interactive Adoption, and Stabilisation of e-commerce.

H8.1, H8.2, H8.3: Security Concern contributes significantly (negatively associated) to NonInteractive Adoption, Interactive Adoption, and Stabilisation of e-commerce.

H9.1, H9.2, H9.3: Relative Advantage contributes significantly to Non-Interactive Adoption, Interactive Adoption, and Stabilisation of e-commerce.

H10.1, H10.2, H10.3: Compatibility contributes significantly to Non-Interactive Adoption, Interactive Adoption, and Stabilisation of e-commerce. 
H11.1, H11.2, H11.3: Complexity contributes significantly to Non-Interactive Adoption, Interactive Adoption, and Stabilisation of e-commerce.

H12.1, H12.2, H12.3: Trialability contributes significantly to Non-Interactive Adoption, Interactive Adoption, and Stabilisation of e-commerce.

H13.1, H13.2, H13.3: Observability contributes significantly to Non-Interactive Adoption, Interactive Adoption, and Stabilisation of e-commerce.

The conceptual model for the study is presented in Figure 1.

Figure 1: The Conceptual Model

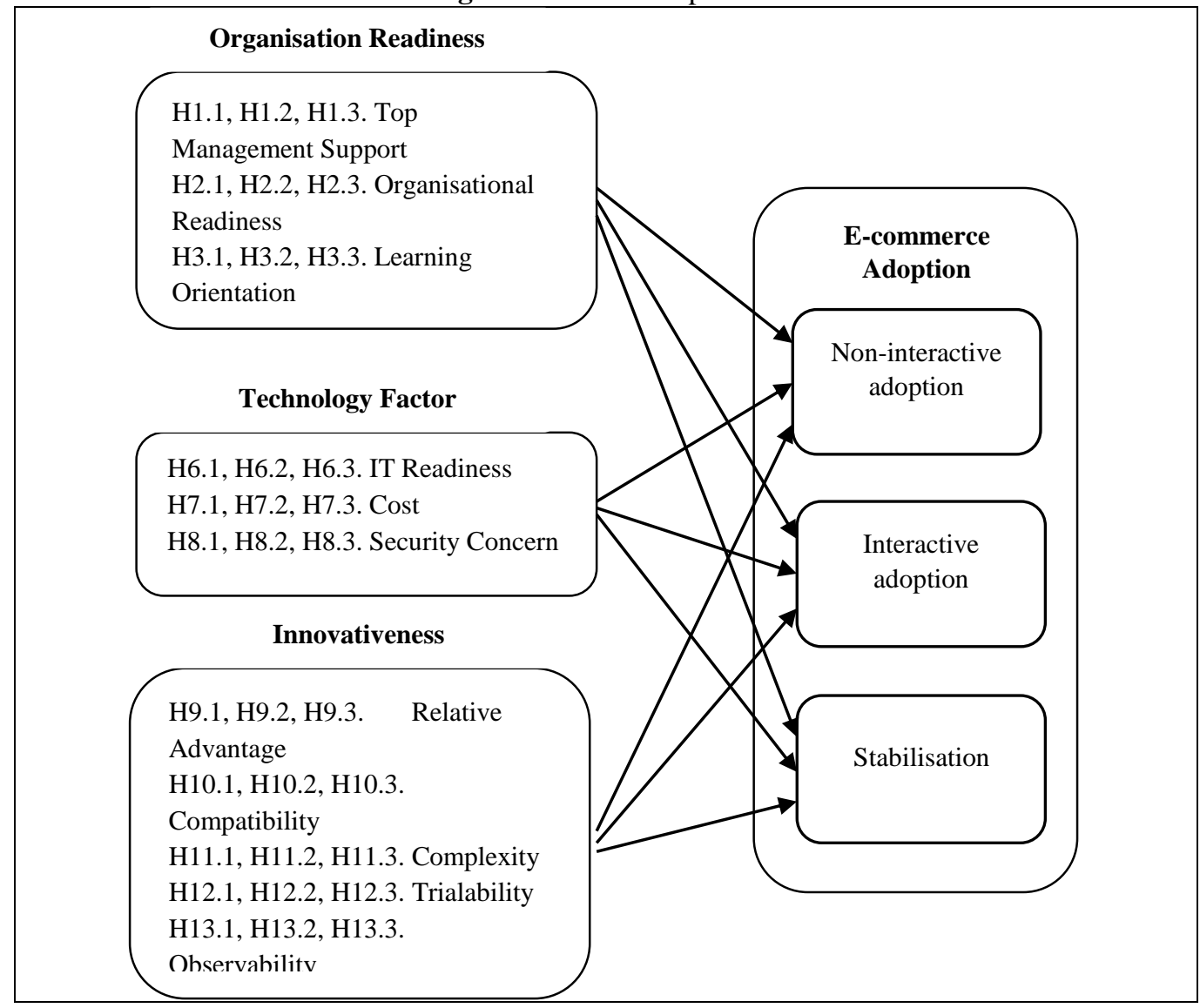




\section{RESEARCH METHODOLOGY}

\subsection{Method and Measures}

A survey method was employed to test the research hypotheses empirically. A structured questionnaire was designed based on the extensive literature review. The questionnaire had two sections. The first section captured general information about respondents, and the second section was classified under four categories, namely Organisation Readiness, Technological Factors, Innovativeness, and E-commerce Adoption Stages. The constructs under the categories were measured on a five-point Likert scale starting from 1 for strongly disagree and 5 for strongly agree. The dependent variable 'e-commerce adoption' was measured on a dichotomous scale. Before the questionnaire was administered to target firms, a pilot test was conducted by sending the questionnaire to some experts in the SME sector to evaluate the validity and relevance of the items. Minor corrections were made to the questionnaire based on the experts' suggestions.

\subsection{Respondents}

The Indian manufacturing industry is equally dominated by large-scale organisations and SMEs. SMEs contribute 28.7 per cent to the country's Gross Domestic Product and 33 per cent to the gross value of output. Out of the participant SMEs, 31 per cent were engaged in manufacturing activities, 36 per cent were engaged in trade, and 33 per cent in other services (Government of India, 2018). As per the Coimbatore District Statistical Handbook for 2013-2014, Coimbatore had 12,873 SMEs. The economy of Coimbatore is largely influenced by textiles machinery, auto components, steel and aluminium foundries, pumps and motors, and IT firms (Business Line, 2018). Coimbatore city being a major hub for SMEs, it was reasonable to conduct this study in this part of the country. The questionnaire was distributed to 220 SMEs in Coimbatore and 148 responses were received and used for the analysis. The respondents were employees occupying top-level managerial positions who were sufficiently proficient to fill the questionnaire.

\section{ANALYSIS AND FINDINGS}

\subsection{Reliability and Validity}

Construct reliability is used to assess the degree of consistency between multiple items of a construct. It is tested by calculating Cronbach's alpha coefficient, and its acceptable value is 0.70 (Nunnally, 1978). In this study, all thirteen constructs displayed high Cronbach's alpha coefficient values $>0.75$. The results are presented in Table 1 . Thus, construct reliability is considered to be strong for this study. Convergent validity assesses the extent to which the items measuring a construct converge together and measure a single construct (Hair et al., 2010). A confirmatory factor analysis was carried out during the convergent validity check process. A rule of thumb is that factor loadings should be at least 0.50 or higher with statistically significant factor loadings (Xiaoxia et al., 2012). Following the aforementioned rules, five items that were $<0.5$ were omitted from the original conceptual questionnaire. The items with factor loadings $>0.5$ were retained for the study. The results are presented in Table 1 and indicate high convergent validity. 
Table 1: Reliability and Validity Scores

\begin{tabular}{|c|c|c|c|}
\hline Construct & Item & $\begin{array}{c}\text { Factor } \\
\text { Loading }\end{array}$ & Cronbach's alpha \\
\hline \multirow{5}{*}{ Top Management Support } & TopMgt1 & 0.5603 & $\alpha=0.7380$ \\
\hline & TopMgt2 & 0.5909 & \\
\hline & TopMgt3 & 0.5418 & \\
\hline & TopMgt4 & 0.7178 & \\
\hline & TopMgt5 & 0.6725 & \\
\hline \multirow[t]{3}{*}{ Organisational Competence } & OrgCmp1 & 0.6815 & $\alpha=0.7107$ \\
\hline & OrgCmp2 & 0.5805 & \\
\hline & OrgCmp3 & 0.5914 & \\
\hline \multirow[t]{5}{*}{ Learning Orientation } & LrnOr1 & 0.6134 & $\alpha=0.7805$ \\
\hline & LrnOr2 & 0.5635 & \\
\hline & LrnOr3 & 0.5973 & \\
\hline & LrnOr4 & 0.6490 & \\
\hline & LrnOr5 & 0.6463 & \\
\hline \multirow[t]{5}{*}{ Receptivity towards Change } & Change1 & 0.6324 & $\alpha=0.7596$ \\
\hline & Change2 & 0.5771 & \\
\hline & Change 3 & 0.5065 & \\
\hline & Change4 & 0.5742 & \\
\hline & Change5 & 0.5738 & \\
\hline \multirow[t]{9}{*}{ Strategic Orientation } & StrOr1 & 0.6371 & $\alpha=0.8607$ \\
\hline & StrOr2 & 0.6012 & \\
\hline & StrOr3 & 0.5820 & \\
\hline & StrOr4 & 0.6178 & \\
\hline & StrOr5 & 0.6846 & \\
\hline & StrOr6 & 0.6448 & \\
\hline & StrOr7 & 0.5475 & \\
\hline & StrOr8 & 0.5409 & \\
\hline & StrOr9 & 0.5034 & \\
\hline \multirow[t]{7}{*}{ IT Readiness } & IT1 & 0.5550 & $\alpha=0.7889$ \\
\hline & IT2 & 0.5497 & \\
\hline & IT3 & 0.5050 & \\
\hline & IT4 & 0.6403 & \\
\hline & IT5 & 0.6164 & \\
\hline & IT6 & 0.5953 & \\
\hline & IT7 & 0.5606 & \\
\hline \multirow[t]{4}{*}{ Cost } & Cost1 & 0.5050 & $\alpha=0.6944$ \\
\hline & Cost2 & 0.5634 & \\
\hline & Cost3 & 0.6020 & \\
\hline & Cost 4 & 0.6333 & \\
\hline \multirow[t]{5}{*}{ Security Concern } & Secu1 & 0.5477 & $\alpha=0.7171$ \\
\hline & Secu2 & 0.5598 & \\
\hline & Secu3 & 0.5549 & \\
\hline & Secu 4 & 0.5378 & \\
\hline & Secu5 & 0.5838 & \\
\hline \multirow[t]{5}{*}{ Perceived Relative Advantage } & RelAdv1 & 0.5963 & $\alpha=0.8242$ \\
\hline & RelAdv2 & 0.6230 & \\
\hline & RelAdv3 & 0.6038 & \\
\hline & RelAdv4 & 0.6120 & \\
\hline & RelAdv5 & 0.6063 & \\
\hline
\end{tabular}




\begin{tabular}{llll} 
& RelAdv6 & 0.6115 & \\
RelAdv7 & 0.5763 & \\
Compatibility & Compat1 & 0.6641 & $\alpha=0.6598$ \\
& Compat2 & 0.6432 & \\
Complexity & Compat3 & 0.5550 & $\alpha=0.7283$ \\
& Compl1 & 0.6986 & \\
Comp12 & 0.5549 & \\
Trialability & Compl3 & 0.5198 & \\
& Comp14 & 0.5338 & \\
& Trial1 & 0.5334 & \\
Trial2 & 0.5585 & $\alpha=0.7738$ \\
Trial3 & 0.5740 & \\
Observability & Obs1 & 0.5676 & \\
& Obs2 & 0.5819 & \\
& Obs4 & 0.5639 & \\
& Obs5 & 0.6070 & \\
& 0.5769 & \\
\hline \hline
\end{tabular}

\subsection{General Profile and Summary Statistics}

The summary of demographic data of the respondents, such as gender, age, education, work experience, and number of employees in the organisation, are presented in Table 2. The results revealed that the data was collected from a reasonable spread of male and female respondents, with 55.4 per cent men and 44.6 per cent women. It was also observed that most respondents were in the age group of 30-40 years (33.7 per cent). The work experience of the employees was predominantly $11-15$ years ( 28.1 per cent). Majority ( 27.6 per cent) of the organisations surveyed had 51-100 employees followed by organisations with 201-500 employees.

Table 2: General Statistics

\begin{tabular}{llc}
\hline \hline \multirow{3}{*}{ Variable } & \multicolumn{1}{c}{ Classification } & Percentage \\
& Male & 55.4 \\
& Female & 44.6 \\
Age & $20-30$ & 26.2 \\
& $30-40$ & 33.7 \\
& $40-50$ & 28.8 \\
& $>50$ & 11.3 \\
& $1-5$ years & 15.8 \\
Work Experience & $6-10$ years & 18.9 \\
& $11-15$ years & 28.1 \\
& $16-20$ years & 19 \\
& $21-25$ years & 11.4 \\
& $>25$ years & 6.8 \\
Number of Employees in the & $0-50$ Employees & 19.1 \\
Organisation & $51-100$ Employees & 27.6 \\
& $101-200$ Employees & 14.1 \\
& $201-500$ Employees & 20.8 \\
& $>500$ Employees & 18.4 \\
\hline \hline
\end{tabular}




\subsection{Hypotheses Tests}

The conceptual model was tested empirically by using binomial logistic regression. This multivariate statistical technique was selected because the dependent variables (Non-Interactive adoption, Interactive adoption, and Stabilisation) used in this study are dichotomous (Hair et al., 2010).

\subsubsection{Non-interactive adoption}

Hair et al. (2010) have indicated that the classification ability test can be used to assess the accuracy of a model in classifying respondents into correct groups. In this study, the classification table examines the capability of the model to correctly classify adopters and non-adopters into their respective groups. Table 3 presents the classification table for Non-interactive e-commerce adoption. The logistical model has an overall prediction accuracy of 62.2 per cent. The table further reveals that there are 58 adopters and 90 non-adopters; the classification accuracy is $(58 / 148)^{2}+$ $(90 / 148)^{2}=52.3$ per cent. Therefore, the logistic regression model has better classification ability.

Table 3: Classification Table for Non-Interactive Adoption

\begin{tabular}{llccc}
\hline \hline \multirow{2}{*}{ Observed } & \multicolumn{3}{c}{ Predicted } \\
\cline { 2 - 5 } & & Adopters & Non-Adopters & Percentage Correct \\
\hline \multirow{2}{*}{ NIADOPT } & Adopters & 28 & 30 & 46.9 \\
& Non-Adopters & 26 & 64 & 73.8 \\
& Overall Percentage & & 62.2 \\
\hline \hline
\end{tabular}

The Wald statistic test was performed to measure the level of significance and contribution of individual coefficients in the model (Hair et al., 2010). The results from Table 4 indicate that under the category Organisational Readiness, the significance of constructs, such as Top Management Support, Learning Orientation, Receptivity towards Change, and Strategic Orientation, was less than the level of significance $(\alpha=0.05)$, which indicates a significant influence on Non-Interactive e-commerce adoption. Hence, the hypotheses H1.1, H3.1, H4.1, and H5.1 are accepted. In the Technology Factors category, the significance values of IT Readiness and Cost (negatively related) are $<0.05$, which indicates a strong influence on the dependent variable. Hence, the hypotheses H6.1 and H7.1 are accepted. None of the constructs under the third factor Innovativeness influenced Non-Interactive e-commerce adoption.

Table 4: Logistic Regression for Non-Interactive Adoption

\begin{tabular}{lcccccr}
\hline \hline \multicolumn{1}{c}{ Constructs } & B & S.E. & Wald & Df & Sig. & Exp(B) \\
\hline TopMgt & .183 & .353 & .268 & 1 & .039 & 1.201 \\
OrgCmp & -.096 & .289 & .112 & 1 & .738 & .908 \\
LrnOr & .182 & .393 & .216 & 1 & .036 & .833 \\
Change & .354 & .342 & 1.074 & 1 & .010 & .702 \\
StrOr & .027 & .418 & .004 & 1 & .044 & .974 \\
ITReady & .082 & .378 & .046 & 1 & .011 & .922 \\
Cost & -.715 & .380 & 3.551 & 1 & .013 & .489 \\
Security & .132 & .314 & .177 & 1 & .674 & 1.141 \\
\hline \hline
\end{tabular}




\begin{tabular}{llrrrrr}
\hline \hline \multicolumn{1}{c}{ Constructs } & B & S.E. & Wald & Df & \multicolumn{1}{c}{ Sig. } & Exp(B) \\
\hline RelAdv & .645 & .451 & 2.042 & 1 & .020 & 1.906 \\
Compat & .173 & .326 & .282 & 1 & .595 & 1.189 \\
Compl & .237 & .305 & .603 & 1 & .438 & 1.267 \\
Trial & -.360 & .294 & 1.496 & 1 & .221 & .698 \\
Obs & .086 & .365 & .055 & 1 & .815 & 1.089 \\
\hline \hline
\end{tabular}

\subsubsection{Interactive adoption}

The classification table for Interactive e-commerce adoption is presented in Table 5. Based on the observed-predicted section, the rate of correct predictions by the model was computed. The model has an overall prediction accuracy of 70.3 per cent. There are 99 adopters and 49 non-adopters and the classification accuracy is $(99 / 148)^{2}+(49 / 148)^{2}=55.7$ per cent. Thus, the model is claimed to have better classification ability.

Table 5: Classification Table for Interactive Adoption

\begin{tabular}{llccc}
\hline \hline Observed & & \multicolumn{3}{c}{ Predicted } \\
\cline { 3 - 5 } & & Adopters & Non-Adopters & Percentage Correct \\
\hline IAdopt & Adopters & 90 & 9 & 90.9 \\
& Non-Adopters & 35 & 14 & 28.6 \\
& \multicolumn{2}{c}{ Overall Percentage } & & 70.3 \\
\hline \hline
\end{tabular}

Table 6 presents the results of the Wald test for Interactive e-commerce adoption. Under the category Organisational Readiness, the significance of constructs, such as Top Management Support, Learning Orientation, Receptivity towards Change, and Strategic Orientation are $<0.05$. This indicates that they strongly influenced a firm's decision to implement Interactive e-commerce. Hence, the hypotheses H1.2, H3.2, H4.2, and H5.2 are accepted. Under the second category Technology Factor, the constructs IT Readiness and Cost (negatively associated) significantly influenced Interactive e-commerce adoption. As per the results, H6.2 and H7.2 are accepted. The Innovative factor also influences Interactive e-commerce adoption because the significance values of constructs Complexity, Trialability, and Observability are $<0.05$. Based on the results, the hypotheses H11.2, H12.2, and H13.2 are accepted.

Table 6: Logistic Regression for Interactive Adoption

\begin{tabular}{lrrrrrr}
\hline \multicolumn{1}{c}{ Constructs } & B & \multicolumn{1}{c}{ S.E. } & \multicolumn{1}{c}{ Wald } & df & \multicolumn{1}{c}{ Sig. } & Exp(B) \\
\hline TopMgt & .365 & .370 & .977 & 1 & .027 & .694 \\
OrgCmp & -.466 & .308 & 2.282 & 1 & .631 & .628 \\
LrnOr & .324 & .398 & .662 & 1 & .016 & 1.382 \\
Change & .504 & .354 & 2.031 & 1 & .040 & .604 \\
StrOr & .532 & .448 & 1.412 & 1 & .019 & 1.703 \\
ITReady & .415 & .393 & 1.114 & 1 & .000 & .661 \\
Cost & -.388 & .369 & 1.107 & 1 & .000 & .678 \\
Security & .245 & .321 & .586 & 1 & .444 & 1.278 \\
RelAdv & -.388 & .478 & .658 & 1 & .056 & .678 \\
Compat & .408 & .340 & 1.441 & 1 & .230 & 1.504
\end{tabular}




\begin{tabular}{lccccrr}
\hline \hline \multicolumn{1}{c}{ Constructs } & B & S.E. & Wald & df & \multicolumn{1}{c}{ Sig. } & \multicolumn{1}{c}{$\operatorname{Exp(B)}$} \\
\hline Compl & .173 & .319 & .295 & 1 & .000 & .841 \\
Trial & .281 & .313 & .805 & 1 & .000 & 1.324 \\
Obs & .294 & .398 & .546 & 1 & .000 & 1.342 \\
\hline \hline
\end{tabular}

\subsubsection{Stabilisation}

The classification ability test for stabilised e-commerce adoption by SMEs is presented in Table 7 . The model has an overall prediction accuracy of 81.8 per cent. Table 7 further indicates that there are 59 adopters and 89 non-adopters. The classification accuracy is $(59 / 148)^{2}+(89 / 148)^{2}=52.0$ per cent. This indicates that the model has better classification ability.

Table 7: Classification Table for Stabilisation

\begin{tabular}{llccc}
\hline \hline \multirow{2}{*}{ Observed } & \multicolumn{3}{c}{ Predicted } \\
\cline { 2 - 5 } & & Adopters & Non-Adopters & Percentage Correct \\
\hline \multirow{2}{*}{ Stablise } & Adopters & 46 & 13 & 78.0 \\
& Non-Adopters & 14 & 75 & 84.3 \\
& \multicolumn{2}{c}{ Overall Percentage } & & 81.8 \\
\hline \hline
\end{tabular}

Table 8 reveals constructs that influence stabilised e-commerce adoption in SMEs. The results indicate that the significance for constructs such as Top Management Support, Learning Orientation, Receptivity towards Change, and Strategic Orientation is $<0.5$, and they influence ecommerce adoption. Hence, hypotheses H1.3, H3.3, H4.3, and H5.3 are accepted. Under the second factor, IT Readiness (H6.3) and Cost (H7.3, negatively associated) have significance values $<0.05$, and are considered as strong factors that influence Stabilised e-commerce adoption. In addition, the Innovative factor becomes a significant factor positively influencing e-commerce adoption because the constructs Compatibility, Complexity, Trialability, and Observability have significance values $<0.05$. As per the results, the hypotheses H10.3, H11.3, H12.3, and H13.3 are accepted.

Table 8: Logistic Regression for Stabilisation

\begin{tabular}{lrrrrrr}
\hline \hline \multicolumn{1}{c}{ Constructs } & \multicolumn{1}{c}{ B } & \multicolumn{1}{c}{ S.E. } & Wald & Df & \multicolumn{1}{c}{ Sig. } & Exp(B) \\
\hline TopMgt & 1.209 & .491 & 6.053 & 1 & .014 & .299 \\
OrgCmp & .252 & .397 & .405 & 1 & .525 & 1.287 \\
LrnOr & .794 & .542 & 2.151 & 1 & .025 & .452 \\
Change & .195 & .422 & .214 & 1 & .000 & 1.216 \\
StrOr & .612 & .524 & 1.362 & 1 & .099 & 1.843 \\
ITReady & .400 & .478 & .699 & 1 & .045 & .670 \\
Cost & -.309 & .505 & .376 & 1 & .024 & .734 \\
Security & -.034 & .401 & .007 & 1 & .933 & .967 \\
RelAdv & .126 & .553 & .052 & 1 & .000 & .882 \\
Compat & .104 & .440 & .056 & 1 & .000 & 1.109 \\
Compl & .590 & .411 & 2.062 & 1 & .045 & .554 \\
Trial & .252 & .398 & .399 & 1 & .000 & .777 \\
Obs & .297 & .445 & .444 & 1 & .038 & .743 \\
\hline \hline
\end{tabular}


In this study, the three-stage model of e-commerce adoption among SMEs in India was empirically tested. Empirical evidence indicates that the considerable variability among Non-Interactive adopters, Interactive adopters, and Stabilisation of e-commerce was because of significantly different Organisational, Technological, and Innovative determinants. Figure 2 summarises the key findings of the current study.

Figure 2: Summary of Key Findings

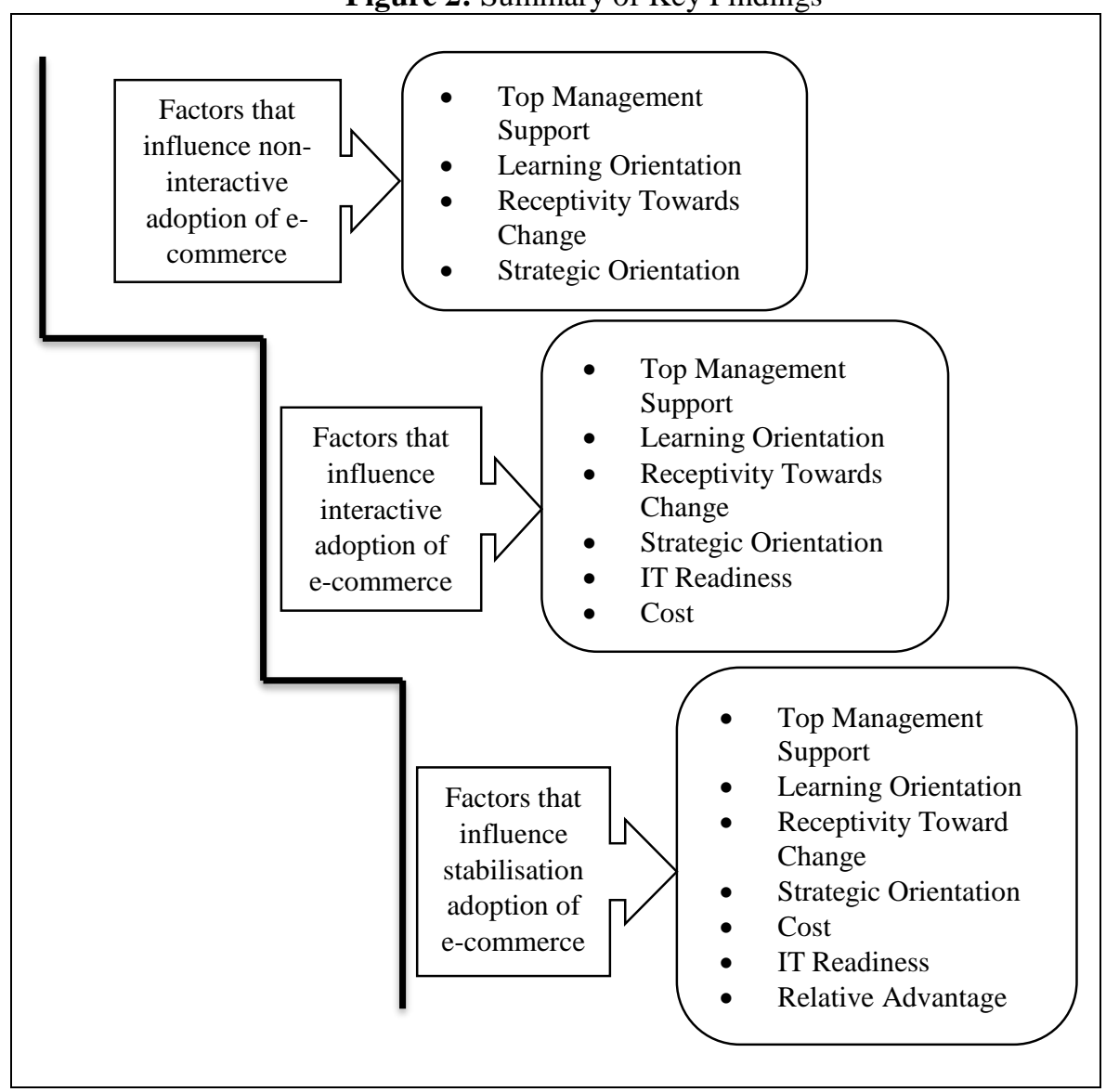

\section{DISCUSSION AND IMPLICATIONS}

The benefit of this model is that it can simultaneously measure the factors and the stages that affect e-commerce adoption. Managers in a firm have the great responsibility to promote e-commerce adoption and support the business. Top management support is the most critical determinant of all three types of adoption of e-commerce in this study. This is consistent with studies such as Saffu et al. (2008), Seyal et al. (2007), Xiaoxia et al. (2012), and Ramdansyah and Taufik (2017). In SMEs, the primary decision-maker is the owner or the chief manager of the business. They should 
be willing to provide necessary resources and track the latest developments in the technology. The top management must be fully aware of the potential benefits of adopting Internet-related business practices.

This study signifies the importance of organisational learning and its effect on e-commerce adoption. The SMEs must be vigilant to learn about new technologies emerging in the market to gain competitive advantage. This result is consistent with the findings of Nikolaeva (2006), Saffu et al. (2008) and Xiaoxia et al. (2012). Employees should be advised to continually improve and encouraged to exchange and share information freely and frequently. Receptivity towards change has emerged as a strong factor influencing e-commerce adoption. This result is consistent with findings of other studies such as Al-Somali et al. (2015) and Marasini et al. (2008). As competition in the global scenario is increasing, it is becoming imperative that SMEs respond to competitor moves in the business environment. The analysis provided strong evidence for SMEs to consider adopting e-commerce as a strategic tool to identify customers' future needs and to meet business objectives. SMEs can closely work with customers and suppliers by embracing e-commerce. Hence, having a strong Strategic Orientation is critical for SMEs to adopt all three stages of Noninteractive, Interactive, and Stabilisation e-commerce.

IT readiness has emerged as an essential factor influencing adoption (Li \& Xie, 2012; Oliveira \& Marins, 2010; Rahayu \& Day, 2015). SMEs must embrace ICT because lack of knowledge, limited awareness, and low levels of Internet penetration may hinder business. Hence, we conclude that high level of IT resources and personnel with IT knowledge will positively affect e-commerce adoption. For SMEs with limited resources, cost is a significant factor for adoption of e-commerce. High set-up costs, cost incurred because of the change, cost of software, and training costs become inhibiting factors for e-commerce adoption. As the cost of implementation increases, the possibility of e-commerce adoption decreases. The implication for software developers and service providers is to embrace and develop cost-effective technology solutions to encourage SMEs to adopt ecommerce.

In this study, it is revealed that the Innovativeness category has become a strong influencing factor for adopting Interactive and Stabilised e-commerce in an organisation. The overall results confirm the Rogers (1995) theory regarding the influence of innovation characteristics on e-commerce adoption. Compatability, trialability, and observability are predictors for Interactive e-commerce adoption; however, all five constructs of the diffusion innovation theory influence Interactive and Stabilisation e-commerce. SMEs should believe that e-commerce enhances their corporate image and establishes stronger links with clients and other partners. Further, they must understand that ecommerce reduces the cost of information gathering and doing business. These perceived advantages will positively affect e-commerce adoption. Evidence from this study suggests that SMEs with an efficient infrastructure and organisational climate are more likely to adopt ecommerce. Trialability positively affects Stabilisation e-commerce adoption. Because of advances in technology and because India is growing in software development, SMEs should be able to access a free trial of the e-commerce software and experiment with e-commerce tools. Complexity negatively affects e-commerce adoption. This is consistent with the study done by Alam et al. (2008). The more complex a new technology is, the less likely it is to be adopted by organisations. These results send strong signals for technology service providers to develop user friendly and less complex software solutions with less interactive steps for users to complete a transaction. 
The most crucial implication from this study to managers/owners of SMEs is that e-commerce is a strategic tool for information gathering, marketing, and providing customer service. Managers should ensure that they are able to acquire the technical knowledge related to e-commerce adoption. The continued growth of e-commerce will enable companies to engage in doing business across borders.

\section{CONCLUSION}

In this study, factors influencing e-commerce adoption were successfully demonstrated with the help of the three-stage model that includes three types of factors (Organisational Readiness, Technology Factors, and Innovativeness) and three different stages (Non-Interactive, Interactive, and Stabilisation) of e-commerce. The results of this study revealed a list of factors that affect ecommerce adoption by SMEs in India. The study provides directions to the manager/owner, technology consultants, and software vendors who are involved in implementing e-commerce for SMEs. The managers should provide a conducive environment to experiment, learn, and adopt new technologies. Change management mechanism should be evolved to guide employees by providing adequate training and helping them overcome apprehension of using new technologies. Aligning e-commerce initiatives towards a strategic intent will benefit the SMEs. In addition, the organisations that perceive the benefits are more likely to adopt e-commerce. Hardware and software vendors should take the opportunity of developing cost-effective and robust ICT tools to meet the specific needs of SMEs. As SMEs are numerous, vendors can tap this opportunity for mutual benefit by SMEs adopting e-commerce. The IT industry is growing in India (Nasscom, 2018), and SMEs should leverage this growth for efficient e-commerce usage. In future, this model can be used to elaborate the research in many directions by including non-profit, manufacturing, and service organisations. Further collecting multiple responses from a single organisation and including various industry segments will help gather other factors that affect an SME organisation's willingness to adopt e-commerce.

\section{REFERENCES}

Ahmad, S. Z., Bakar, A. R. A., Faziharudean, T. M., \& Zaki, K. A. M. (2015). An empirical study of factors affecting e-commerce adoption among small and medium-sized enterprises in a developing country: Evidence from Malaysia. Information Technology for Development, 21(4), 555-572. https://doi.org/10.1080/02681102.2014.899961

Al-Alawi, A. I., \& Al-Ali, F. M. (2015). Factors affecting e-commerce adoption in SMEs in the GCC: An empirical study of Kuwait. Research Journal of Information Technology, 7(1), 1-21. https://doi.org/10.3923/rjit.2015.1.21

Alam, S. S., Khatibi, A., Ahmad, M. I. S., \& Ismail, H. B. (2008). Factors affecting e-commerce adoption in the electronic manufacturing companies in Malaysia. International Journal of $\begin{array}{llll}\text { Commerce } \quad \text { and } & \text { Management, } & \text { 17(1/2), }\end{array}$ https://doi.org/10.1108/10569210710776503

Al-Qirim, N. (2005). An empirical investigation of an e-commerce adoption-capability model in small businesses in New Zealand. Electronic Markets, 15(4), 263-28. https://doi.org/10.1080/10196780500303136 
Al-Somali, S. A., Gholami, R., \& Clegg, B. (2015). A stage-oriented model (SOM) for ecommerce adoption: A study of Saudi arabian Organisation. Journal of Manufacturing Technology Management, 22(1), 2-35. https://doi.org/10.1108/JMTM-03-2013-0019

Awiagah, R., Kang, J., \& Lim, J. I. (2016). Factors affecting e-commerce adoption among SMEs in Ghana. Information $\quad$ Development, 32(4), 815-836. https://doi.org/10.1177/0266666915571427

Belkhamza, Z., \& Wafa, S. (2009). The effect of perceived risk on the intention to use e-commerce: The case of Algeria. Journal of Internet Banking and Commerce, 14(1), 1-10.

Business Line. (2018). Why Coimbatore hums with industrial energy. Retrieved July 20, 2019 from https://www.thehindubusinessline.com/news/why-coimbatore-hums-with-industrialenergy/article9740435.ece.

Chaudhury, A., \& Kuilboer, J. P. (2002). E-Business and Infrastructure. Boston: McGraw-Hill, 2002.

Chong, S. (2008). Success in electronic commerce implementation - a cross-country study of small and medium-sized enterprises. Journal of Enterprise Information Management, 21(5), 468492. https://doi.org/10.1108/17410390810904247

Cooper, R. B., \& Zmud, R. W. (1990). Information technology implementation research: A technological diffusion approach. Management Science, 36(2), 123-139. https://doi.org/10.1287/mnsc.36.2.123

Ghobakhloo, M., \& Tang, S. H. (2013). The role of owner/manager in adoption of electronic commerce in small businesses. Journal of Small Business and Enterprise Development, 20(4), 754-787. https://doi.org/10.1108/JSBED-12-2011-0037

Globerman, S., Roehl, T. W., \& Standifird, S. (2001). Globalization and electronic commerce. Journal of International Business Studies, 32(4), 749-68.

Government of India. (2018). Annual Report 2017-18. Retrieved July 15, 2018 from https://msme.gov.in/sites/default/files/MSME-AR-2017-18-Eng.pdf

Hair, J. F., Anderson, R. E., Tatham, R. L., \& Black, W. C. (2010). Multivariate Data Analysis. New York: Macmillan.

Hartman, A., Sifonis, J., \& Kador, J. (2000). Net Ready: Strategies for Success in the Economy. New York: McGraw-Hill.

Hussein, A., \& Baharudin, A. S. (2017). A case study of e-commerce adoption in Jordanian small and medium enterprises (SMEs). International Journal of Business and Management, 6(9), 8893.

Huy, L. E. V., Rowe, F., \& Truex, D. (2012). An empirical study of determinants of e-commerce adoption in SMEs in Vietnam an economy in transition. Journal of Global Information Management, 20(3), 23-54. https://doi.org/10.4018/jgim.2012070102

Jon, K., Lai, T. L., Khoon, C. H., Dennis, N. C., \& Meng, T. S. (2001). Electronic commerce adoption by SMEs in Singapore. Proceedings of the 34th International Conference on System Sciences.

Kreiser, P. M., Marina, L. D., Dickson, P., \& Weaver, K. M. (2010). Cultural influences on entrepreneurial orientation: The impact of national culture on risk taking and pro-activeness in SMEs. Entrepreneurship theory and practice, 34(5), 959-984. https://doi.org/10.1111/j.15406520.2010.00396.x

Li, P., \& Xie, W. (2012). A strategic framework for determining e-commerce adoption. Journal of Technology Management in China, 7(1), 22-35. https://doi.org/10.1108/17468771211207321 
Marasini, R., Ions, K., \& Ahmad, M. (2008). Assessment of e-business adoption in SMEs: a study of manufacturing industry in the UK north east region. Journal of Manufacturing Technology Management, 19(5), 627-644. https://doi.org/10.1108/17410380810877294

Masarweh, M. A., Al-Masaeed, J. S., Al-Qaisi, J. L., \& Hunaiti, J. Z. (2016). E-commerce adoption at customer level in Jordan: An empirical study of Philadelphia general supplies. International Journal of Advanced Computer Science and Applications, 7(11), 196-205.

Moghavvemi, S., Hakimian, F., \& Feissal, T. (2012). Competitive advantage through it innovation adoption by SMEs. Social Technologies, 2(1), 24-39.

Molla, A., \& Licker, P.S. (2005a). Ecommerce adoption in developing countries: A model and instrument. Information and Management, 42(6), 877-899. https://doi.org/10.1016/j.im.2004.09.002

Molla, A., \& Licker, P. S. (2005b). Perceived e-readiness factors in e-commerce adoption: An empirical investigation in a developing country. International Journal of Electronic Commerce, 10(1), 83-110.

Nasscom. (2018). Research and Intelligence. Quarterly Industry Review. Retrieved August 30, 2019 from https://nasscom.in/knowledge-center/publications/quarterly-industry-review-june2018

Ndayizigamiye, P. (2012). A unified approach towards e-commerce adoption by SMEs in South Africa. International Journal of Information Technology and Business Management, 16(1), 92101.

Nezakati, H., Jofreh, M., Liong, G., \& Asgari, O. (2012). Assessing e-commerce adoption by small and medium enterprises in Malaysia, Singapore and Thailand. World Applied Sciences Journal, 19(10), 1406-1411. https://doi.org/10.5829/idosi.wasj.2012.19.10.3659

Nikolaeva, R. (2006). E-commerce adoption in the retail sector: Empirical insights. International Journal of Retail \& Distribution Management, 34(4/5), 369-387. https://doi.org/10.1108/09590550610660288

Nunnally, J. C. (1978). Psychometric Theory (2 ${ }^{\text {nd }}$ ed.). New York: McGraw-Hill.

Oliveira, T., \& Martins, M. F. (2010). Understanding e-business adoption across industries in European countries. Industrial Management \& Data Systems, 110(9), 1337-1354. https://doi.org/10.1108/02635571011087428

Parker, C. M., \& Castleman, T. (2009). Small firm e-business adoption: A critical analysis of theory. Journal of Enterprise Information Management, 22(1/2), 167-182. https://doi.org/10.1108/17410390910932812

Rahayu, R., \& Day, J. (2015). Determinant factors of e-commerce adoption by SMEs in developing country: Evidence from Indonesia. Procedia - Social and Behavioral Sciences, 195(3), 142150. https://doi.org/10.1016/j.sbspro.2015.06.423

Rahayu, R., \& Day, J. (2017). E-commerce adoption by SMEs in developing countries: Evidence from Indonesia. Eurasian Business Review, 7(1), 25-41. https://doi.org/10.1007/s40821-016$\underline{0044-6}$

Ramdansyah, A. D., \& Taufik. H. E. R. (2017). Adoption model of e-commerce from SMEs perspective in developing country evidence - case study for Indonesia. European Research Studies Journal, 20(4B), 227-24.

Rogers, E. M. (1995). Diffusion of Innovations (4th ed.). New York: The Free Press.

Saffu, K., Walker, J. H., \& Hinson, R. (2008). Strategic value and electronic commerce adoption among small and medium-sized enterprises in a transitional economy. Journal of Business \& Industrial Marketing, 23(6), 395-404. https://doi.org/10.1108/08858620810894445 
Schulze, C., \& Baumgartner, J. (2000). Don't panic, do e-commerce, a beginner's guide to European law affecting ecommerce. European commission's electronic commerce team.

$\begin{array}{llll}\text { Retrieved January } & 19, & 2019 & \text { from }\end{array}$ https://win.dariocopellino.com/public/download/dont_panic.pdf.

Seyal, A. H., Rahman, M. N. A., Yussof, H. A., \& Mohammad, H. A. (2007). A quantitative analysis of factors contributing electronic data interchange adoption among Bruneian SMEs. $\begin{array}{lllll}\text { Business Process } & \text { Management }\end{array}$ https://doi.org/10.1108/14637150710823183

Terzi, N. (2011). The impact of e-commerce on international trade and employment, Procedia Social and Behavioral Sciences, 24(1), 745-753. https://doi.org/10.1016/j.sbspro.2011.09.010

Titi, K. M. (2005). The impact of adoption electronic commerce in small to medium enterprises Jordanian companies (pp. 159-178). Proceedings of the 1st International Conference on eBusiness and E-Learning.

Turban, E., King, D., Lee, J., Warkentin, M., \& Chung, H. M. (2002). Electronic Commerce (2 ${ }^{\text {nd }}$ ed.). New Jersey, Englewood Cliffs: Prentice-Hall.

Xiaoxia, D., Deng, H., \& Corbitt, B. (2012). Evaluating the critical determinants for adopting emarket in Australian small and medium sized enterprises. Management Research Review, 35(3/4), 289-308. https://doi.org/10.1108/01409171211210172

Zaied, A. N. H. (2012). Barriers to e-commerce adoption in Egyptian SMEs. International Journal of Information Engineering and Electronic Business, 3(1), 9-18. https://doi.org/10.5815/ijieeb.2012.03.02

Zaltman, G., Duncan, R., \& Holbek, J. (1973). Innovations and Organizations. New York: Wiley. Zhao, J., Huang, W. V., \& Zhu, Z. (2008). An empirical study of e-business implementation process in China. IEEE Transactions on Engineering Management, 55(1), 134-147. https://doi.org/ 10.1109/TEM.2007.912930 